\title{
Linfoma anaplásico de células T grandes primario cutáneo CD30+. Serie de nueve casos
}

\author{
León Felipe Ruiz-Arriaga, ${ }^{1}$ Ixchel Landgrave-Gómez, ${ }^{2}$ Sonia Toussaint-Caire, ${ }^{1}$ Rosa María Lacy-Niebla ${ }^{1}$ y \\ María Elisa Vega-Memije ${ }^{1}$

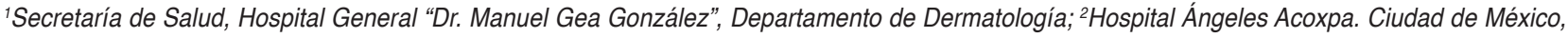 \\ México
}

\section{Resumen}

Introducción: El linfoma anaplásico de células T grandes CD30+ es un linfoma primario cutáneo en el cual no hay evidencia de enfermedad sistémica; para su diagnóstico es necesario el estudio histopatológico. Objetivo: Presentar los casos diagnosticados en el Departamento de Dermatología del Hospital General "Dr. Manuel Gea González" con linfomas anaplásicos de células T grandes primarios cutáneos CD30+ durante un periodo de 24 años. Método: Estudio retrospectivo en el que realizó estadística descriptiva. Se recopiló información de sexo, edad, características clínicas, resultados de pruebas complementarias, tratamientos previos y actuales, reportes de los estudios histopatológicos y de inmunohistoquímica. Resultados: Entre 29309 expedientes, se encontraron nueve casos $(0.000034 \%)$ con diagnóstico de linfoma anaplásico de células T CD30+. Se hizo la confirmación del diagnóstico histopatológico e inmunohistoquímico por dos dermatopatólogos certificados. La edad promedio fue de 61.2 años, hubo predominio del sexo femenino y de lesión papular o nodular y topografía variada como presentación clínica inicial. Conclusiones: El pronóstico del linfoma anaplásico de células T grandes CD30+ en la población estudiada fue dependiente del estadio clínico. El tratamiento en etapas tempranas tiene resultados favorables.

PALABRAS CLAVE: Linfoma anaplásico de células T grandes CD30+. Linfoma cutáneo primario. Trastorno linfoproliferativo cutáneo primario.

\begin{abstract}
Introduction: $\mathrm{CD} 30+$ anaplastic large $T$ cell lymphoma is a cutaneous primary lymphoma in which there is no evidence of systemic disease; histopathological study is required for its diagnosis. Objective: To present the cases diagnosed with primary cutaneous CD30+ anaplastic large T-cell lymphoma over a 24-year period in Hospital General "Dr. Manuel Gea González" Department of Dermatology. Method: Retrospective study. Descriptive statistics was carried out. Information was collected on gender, age, clinical characteristics, complementary test results, previous and current treatments, histopathological studies reports and immunohistochemistry test results. Results: Of 29309 records, nine patients (0.000034\%) with a diagnosis of CD30+ anaplastic T cell lymphoma were found. Histopathological and immunohistochemical diagnosis was confirmed by two certified dermatopathologists. Average age was 61.2 years, and there was a predominance of the female gender, with initial clinical presentation as a papular or nodular lesion and varied topography. Conclusions: The prognosis of CD30+ anaplastic large $T$ cell lymphoma in the studied population was dependent on clinical stage. The treatment at early stages has favorable results.
\end{abstract}

KEY WORDS: Anaplastic CD30+ large T cell lymphoma. Primary cutaneous lymphoma. Primary cutaneous lymphoproliferative disorder.

Fecha de recepción: 06-09-2018

Fecha de aceptación: 21-12-2018

DOI:10.24875/GMM.18004656
Gac Med Mex. 2018;154:130-135

Disponible en PubMed

www.gacetamedicademexico.com 


\section{Introducción}

El linfoma cutáneo primario de células T (LCPCT) es un linfoma en piel en el cual no hay evidencia de enfermedad sistémica (extracutánea) en el momento del diagnóstico.

Según la Revisión de la Clasificación de Neoplasias Linfoides de la Organización Mundial de la Salud de 2016, el linfoma de células T CD30+ primario ocupa el segundo lugar en frecuencia, con 25 a $30 \%$, después de la micosis fungoide. ${ }^{1}$ Esta clasificación incluye el espectro desde la papulosis linfomatoide hasta el linfoma anaplásico de células grandes primario (LACGP), pasando por los casos intermedios.

El LACGP es una entidad rara, su incidencia no se conoce con certeza, posiblemente debido a la dificultad de separar esta patología del espectro de linfomas cutáneos primarios CD30+. En una revisión de 2008 de la base de datos de los Institutos Nacionales de Cáncer de Estados Unidos, se identificaron 157 casos de linfoma primario cutáneo de células T CD30+ en un periodo de 30 años. $^{2}$

El diagnóstico requiere un estudio histopatológico, para el cual se prefiere la biopsia excisional sobre la incisional. Histológicamente se observan células con abundante citoplasma pálidamente eosinófilo; el núcleo puede ser redondo o pleomorfo (usualmente en forma de herradura), con un nucléolo prominente. Una cuarta parte de los linfocitos puede ser atípica, pero no aparenta ser anaplásica. ${ }^{3}$ En la periferia de las lesiones 0 en las zonas ulceradas puede haber linfocitos reactivos, histiocitos, eosinófilos y neutrófilos.

Todos los pacientes con sospecha de LACGP deberán ser estadificados, para confirmar o descartar la enfermedad sistémica. Se recomienda el aspirado de médula ósea en pacientes con ausencia de enfermedad sistémica demostrable por imagen. ${ }^{4,5}$ El diagnóstico diferencial se deberá hacer con la papulosis linfomatoide, micosis fungoide transformada, linfoma sistémico, leucemia-linfoma de células $T$ del adulto, linfoma de Hodgkin e hiperplasia linfoide reactiva.

El tratamiento de las lesiones pequeñas o no muy extensas es la radioterapia o escisión con márgenes libres; ${ }^{6}$ el tratamiento de elección en pacientes con enfermedad diseminada de gran extensión o con múltiples recaídas es la monoterapia con metotrexate hasta por tres años continuos. ${ }^{7}$ En pacientes en los que esté contraindicado este medicamento se puede optar por bexaroteno (grado de evidencia 2C) o interferón. ${ }^{8-11}$ En los enfermos que no responden con el tratamiento previo se puede administrar monoterapia con brentuximab/vedotin, gemcitabina, etopósido o doxorubicina liposomal. ${ }^{4,12-15}$ La quimioterapia combinada y el trasplante alogénico de células hematopoyéticas se debe reservar para casos diseminados que no responden al tratamiento indicado. ${ }^{6}$

El pronóstico depende de múltiples factores clínicos e histopatológicos. En estadios tempranos, la supervivencia a cinco años es hasta de $97.5 \%$ para la enfermedad clasificada en T1, cuando se clasifica como T2, de hasta $93 \%$ y para tumores estadio T3, de $77 \% .{ }^{16,17}$

El objetivo de esta comunicación es presentar nueve casos que se diagnosticaron en nuestro hospital como linfomas anaplásicos de células $T$ grandes primarios cutáneos CD30+ durante un periodo de 24 años.

\section{Método}

En este estudio retrospectivo se revisó la base de datos del Departamento de Dermatopatología del Hospital General "Dr. Manuel Gea González" y se obtuvieron los datos de pacientes con diagnóstico de linfoma anaplásico de células $\mathrm{T}$, durante el periodo de 1993 a 2016. Se realizó estadística descriptiva.

Se recopilaron los datos de sexo, edad (en años), características clínicas (topografía, morfología y tiempo de evolución), resultados de pruebas complementarias, tratamientos previos y actuales, reportes de los estudios histopatológicos y el resultado de los estudios de inmunohistoquímica.

De 29309 expedientes se encontraron nueve pacientes con diagnóstico de linfoma anaplásico de células T CD30+, lo que representa $0.000034 \%$.

Se hizo la confirmación del diagnóstico histopatológico e inmunohistoquímico por dos dermatopatólogos certificados. Se realizaron tinciones con hematoxilina y eosina y un panel de inmunohistoquímica, en los que se incluyeron CD3 (células T), CD4 (células T y dendríticas), CD8 (células T), CD20 (células B), CD30 (células precursoras $\mathrm{T}$ inmaduras), EMA (antígeno de membrana epitelial, marcador de múltiples carcinomas), ALK-1 (cinasa del receptor parecido a activina 1, proteína proangiogénica), MUM1 (oncogén del mieloma múltiple 1, marcador para linfomas) y Ki-67 (proteína necesaria para la proliferación celular, por lo que refleja el índice de división de las células de una neoplasia).

Las tinciones de inmunohistoquímica se realizaron con la técnica convencional y de acuerdo con las instrucciones del fabricante.

A cinco de los pacientes se les realizaron exámenes generales (biometría hemática, química sanguínea, 
Tabla 1. Casos de linfoma anaplásico de células grandes primario diagnosticados en el Departamento de Dermatología del Hospital General "Dr. Manuel Gea González", 1994 a 2017

\begin{tabular}{lll}
\hline Caso & Diagnóstico histopatológico & Resultados de las tinciones inmunohistoquímicas \\
\hline 1 & Infiltrado linfocitario atípico, probable linfoma anaplásico de células T & CD3+, CD30+ \\
2 & Trastorno linfoproliferativo CD30+ & CD30+, EMA-, ALK1- \\
3 & $\begin{array}{l}\text { Linfoma anaplásico de células grandes (rico en neutrófilos y eosinófilos) } \\
\text { CD30+ }\end{array}$ & CD30+, CD3+, EMA+, ALK1- \\
4 & Trastorno linfoproliferativo CD30+ & CD20-, CD3+, CD30+, Ki-67 60\% \\
5 & Trastorno linfoproliferativo CD30+ & Citoqueratinas AE1-3-, CD45+, CD3+, CD4+, CD 30+, \\
& & ALK1-, Ki-67 70 \% \\
6 & Infiltración linfoidea atípica CD30+ & CD3+, CD30+, CD20-, CD4-, CD8- \\
7 & Linfoma cutáneo de células T CD30+ & CD4+, CD30+ \\
8 & Micosis fungoide asociada con alteración linfoproliferativa CD30+ & CD3+, CD4+, CD8+, CD30+, MUM1+ \\
9 & Alteración linfoproliferativa positiva para CD30 sugerente de linfoma & CD3+, CD30+, MUM1+, Ki67 40 \% \\
\hline anaplásico de células T grandes & linfoma anaplásico de células grandes CD30+primario. & \\
\hline
\end{tabular}

reactantes de fase aguda), los cuales resultaron normales; a tres pacientes se les realizaron estudios de imagen, sin identificar evidencia de enfermedad diseminada.

\section{Resultados}

Se registraron nueve pacientes, predominaron las mujeres, la edad promedio fue de 61.2 años, topografía y morfología variada y los estudios histológicos fueron compatibles con linfoma; todos con técnica de inmunohistoquímica CD30+. No se descartó ninguna muestra durante el proceso. La topografía principal fue en tronco y nalgas (cuatro pacientes), así como en miembros inferiores y superiores (cuatro pacientes), cara y cuello (tres pacientes); morfológicamente las lesiones se caracterizaron por lesiones papulares eritematosas, únicas o múltiples que evolucionaron a lesiones tumorales nodulares o placas eritemato-violáceas con escama fina en su superficie; el tiempo de evolución promedio fue de dos años y 20 semanas (distribución de cuatro semanas a 10 años). Como estudios y datos adicionales se realizó química sanguínea, biometría hemática y exploración física completa; solo en un paciente se evidenció adenomegalias. Al momento de este informe, tres pacientes se encontraban en vigilancia, con manejo expectante, en cuatro se había perdido el seguimiento debido a que no continuaron su manejo en la institución por decisión propia o por envío a un centro especializado en cáncer, un paciente estaba en tratamiento con fototerapia y uno más con metotrexate.

Histológicamente encontramos cortes de piel con paraqueratosis y fibrina, epidermis con acantosis irregular, así como abundante espongiosis y exocitosis de neutrófilos e hiperpigmentación focal de la capa basal, con característica proliferación linfoide atípica desde la dermis papilar a la dermis reticular profunda, con núcleos prominentes, grandes, hipercromáticos y pleomórficos, así como abundante citoplasma eosinófilo y algunas células de aspecto plasmocitoide. La proliferación rodeaba los vasos sanguíneos y en algunas zonas invadió sus paredes. En la Tabla 1 se resumen los diagnósticos histológicos e inmunohistoquímicos de los nueve casos. Las Figuras 1 a 5 son imágenes clínicas representativas de los casos 1, 2, 3, 4 y 7; en la Figura 6 se muestra un estudio histopatológico representativo. El índice de proliferación determinado por Ki-67 fue de 40 a $70 \%$ en los casos en los que se realizó.

\section{Discusión}

EI LACGP es una entidad poco frecuente, su incidencia no está reportada con certeza; en el Hospital General "Dr. Manuel Gea González" se diagnosticaron nueve casos en un periodo de 24 años, lo que representa $0.000034 \%$ del total de 29309 biopsias registradas; el número de casos fue muy bajo respecto a otros reportes, como la serie de Yu, en la que se reportan 157 casos en 31 años. ${ }^{2}$

La edad promedio fue de 61.2 años (distribución de 23 a 82 años), similar a 61 años reportada en la literatura. ${ }^{2}$ De nuestros nueve casos, seis fueron mujeres $(66.6 \%)$ y tres hombres, en contraste con lo reportado en el estudio de los Institutos Nacionales de 


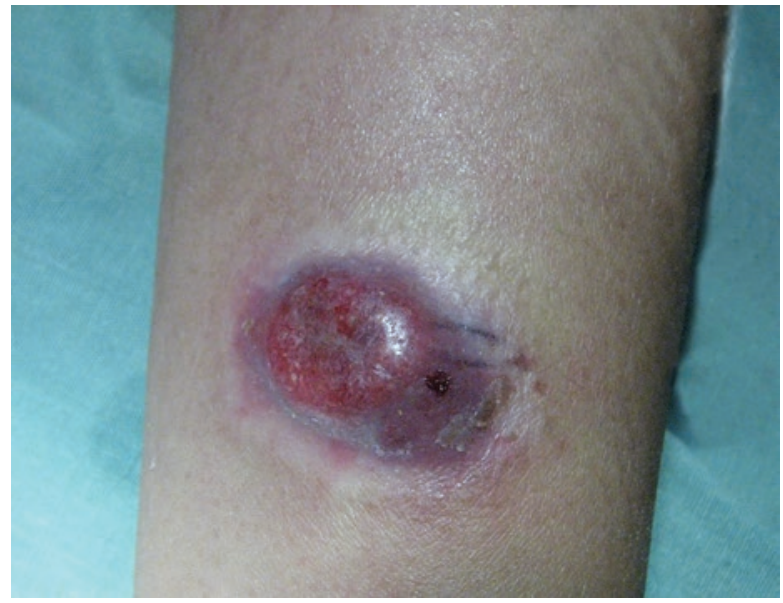

Figura 1. Caso 1. Neoformación de aspecto tumoral sobre placa eritemato-violácea infiltrada en el tercio distal del brazo izquierdo.

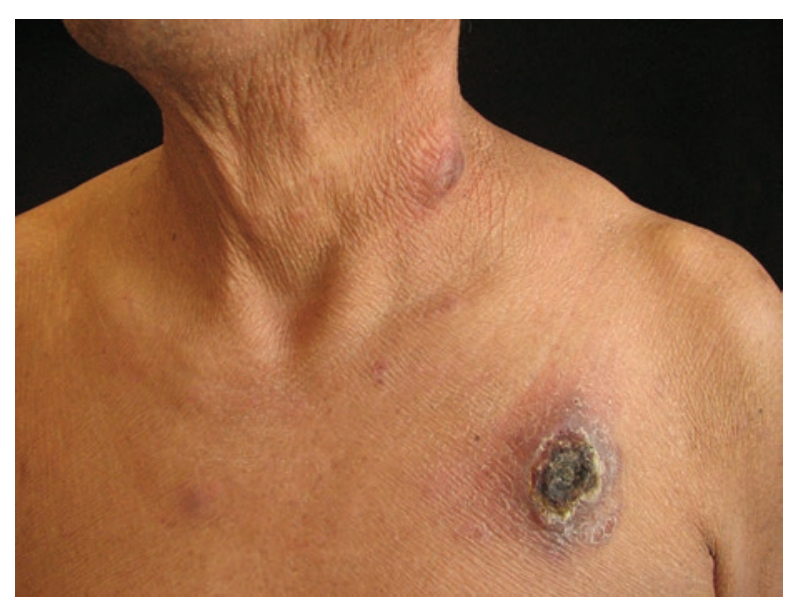

Figura 2. Caso 2. Múltiples lesiones de aspecto tumoral en cuello y tronco anterior, la mayor con costra sanguínea, escama e infiltrada a la palpación.

Cáncer de Estados Unidos, en el cual tuvieron 157 casos, de los que $58 \%$ fue del sexo masculino. ${ }^{2}$

La presentación clínica del LACGP clásicamente consiste en pápulas o nódulos solitarios, agrupados 0 multifocales, en el segmento superior del cuerpo (tronco y miembros torácicos), los cuales persisten de tres a cuatro semanas y tienden a ulcerarse con el tiempo. En nuestros casos, siete pacientes iniciaron con lesiones papulares eritematosas, que evolucionaron a placas eritemato-escamosas bien delimitadas, algunas con bordes infiltrados, ulceradas y de consistencia firme. Cinco pacientes tuvieron lesiones en tronco, cuatro lesiones en extremidades, dos presentaron lesiones en la cara y solo uno tuvo lesiones en el cuello (algunos pacientes tuvieron uno o más sitios afectados). En 20 a $42 \%$ de las casos puede ocurrir resolución espontánea de las lesiones, las cuales no desaparecen del todo, y más de $50 \%$ recurre. ${ }^{6,18-21}$ Debido
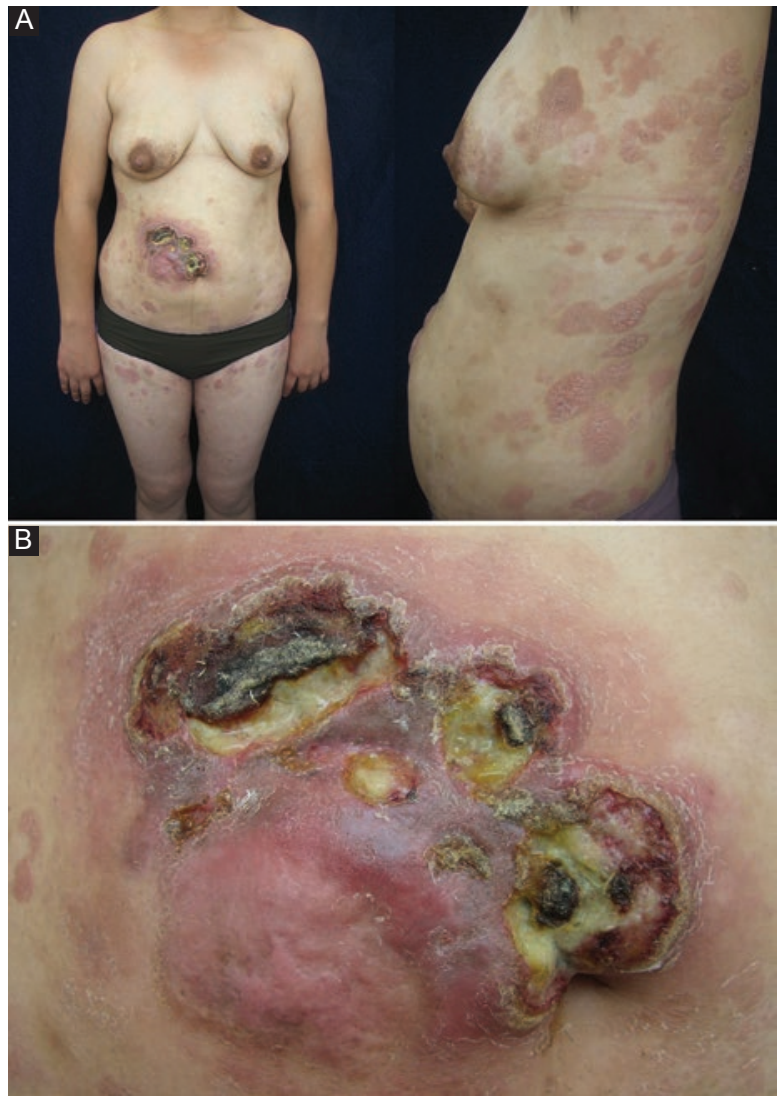

Figura 3. Caso 3. A) Múltiples placas eritemato-escamosas infiltradas en tronco anterior y lateral, así como en cara anterior de muslos, con una tumoración en el abdomen, en la que se identifica una lesión exofítica. B) Acercamiento de la tumoración exofítica, infiltrada y exulcerada con costras.

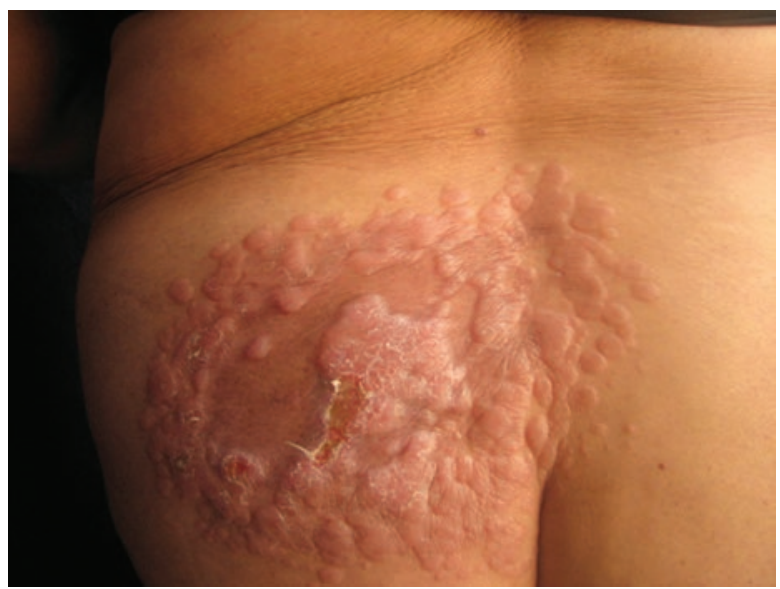

Figura 4. Caso 4. Dermatosis localizada a región lumbosacra constituida por una placa irregular, con múltiples lesiones, sobrelevada en la superficie, color de la piel, con áreas de atrofia y exulceración.

a que los pacientes fueron enviados al Instituto Nacional de Cancerología para tratamiento especializado, se desconoce su evolución.

Histológicamente, la neoplasia se caracteriza por infiltrado dérmico denso y en ocasiones involucra la 


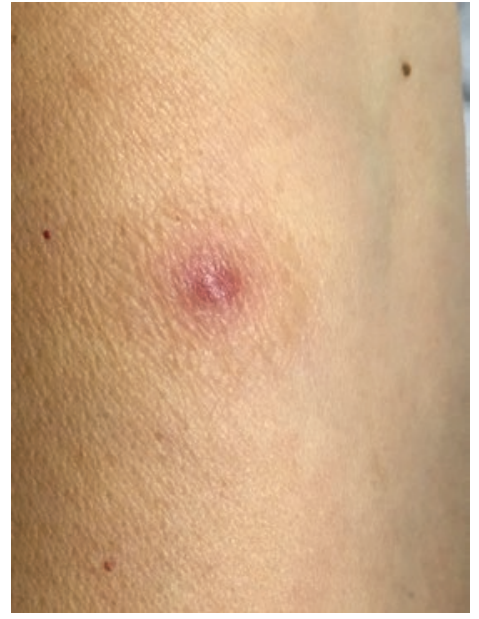

Figura 5. Caso 5. Lesión de aspecto papular, eritematosa con discreta escama en su superficie en la cara anterior del brazo.

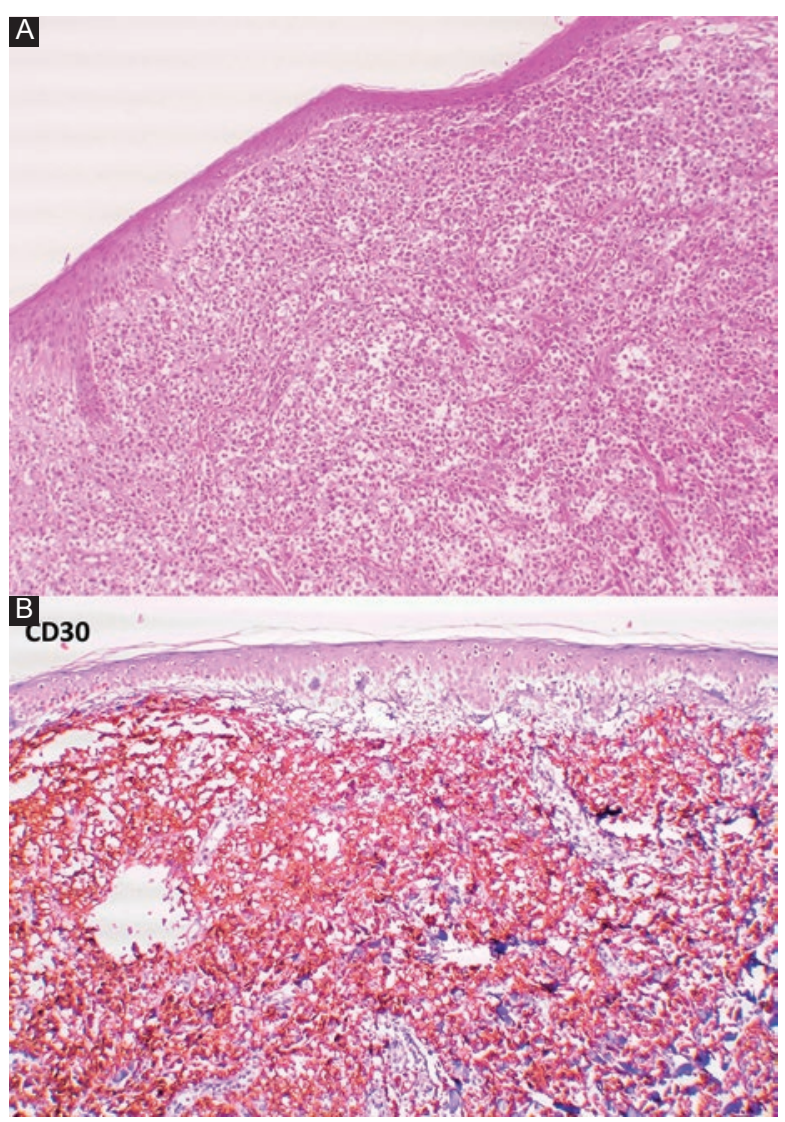

Figura 6. A) Imagen histológica en la que se observa la epidermis con aplanamiento de los procesos interpapilares, la dermis está ocupada por un infiltrado en mantos de células pleomórficas, algunas con citoplasma claro, HE 10x. B) Corte histológico con técnica de inmunohistoquímica intensamente positiva para el anticuerpo CD30, 10x.

epidermis. El infiltrado comprende cúmulos cohesivos de linfocitos grandes, que morfológicamente semejan a los del linfoma anaplásico sistémico de células grandes. ${ }^{22}$ Los cortes histopatológicos mostraron un infiltrado linfocítico difuso, desde la dermis hasta el tejido celular subcutáneo, caracterizado por células medianas-grandes, con pleomorfismo moderado y abundante citoplasma eosinófilo, núcleos prominentes y mitosis atípicas, con algunas células de aspecto plasmocitoide. En uno de nuestros casos se observó infiltración a la vasculatura local.

Por definición, por lo menos $75 \%$ del tumor debe expresar CD30;1,4,23,24 adicionalmente, la mayoría expresa CD4 y pueden tener pérdida variable de CD2, CD3 y CD5. Frecuentemente se evidencia antígeno cutáneo linfocitario y a diferencia del linfoma anaplásico de células grandes sistémico no expresa antígeno de membrana epitelial o ALK-1.1,4,25 Los nueve casos que reportamos fueron positivos para CD30, tres negativos para ALK-1, siete CD3 positivos, dos CD20 negativo, un caso positivo a antígeno de membrana epitelial y uno negativo; en tres se reportó elevado índice de proliferación con Ki-67.

Hay enfermedades que se han asociado con LACGP como la dermatitis atópica, hipersensibilidad a picadura de mosquitos, linfohistiocitosis hemofagocítica y síndrome paraneoplásico de secreción de hormona antidiurética, leucemia mielógena crónica, queratosis liquenoide crónica y carcinoma de células escamosas. ${ }^{26-35} \mathrm{EI}$ paciente 5 de nuestra serie padecía concomitantemente cáncer de próstata avanzado y el paciente 8 , micosis fungoide antes del diagnóstico de LACGP.

También ha sido documentado el LACGP asociado con terapia con carbamazepina; ${ }^{36}$ en nuestros casos, ningún paciente tuvo antecedente de haber ingerido este medicamento. La asociación entre el incremento en la latitud y la prevalencia de linfoma de células $T$, incluyendo al LACGP, sugiere el efecto modulador de la radiación ultravioleta. En nuestro país, la exposición a este tipo de radiación es frecuente y pudiera ser una razón de la baja incidencia de estos casos en nuestra investigación.

El tratamiento indicado fue desde la conducta expectante, por la corta evolución, hasta el manejo en un centro oncológico; uno de los pacientes continuaba con metotrexate en dosis bajas y otro, tratamiento con fototerapia y terapia con baño de electrones debido a la concomitancia con micosis fungoide. Un pacientes solo recibió tratamiento paliativo dada la coexistencia del linfoma con cáncer de próstata en fase terminal.

La recaída después del tratamiento tiende a ser limitada a la piel, pero se ha reportado que $27 \%$ recae con enfermedad extracutánea, la mitad en los nódulos linfáti$\cos ^{17,37}$ La infiltración a órganos internos se puede dar desde dos a 10 años a partir del diagnóstico, según distintos análisis, y no siempre se asocia con estadio $T$ 
avanzado. ${ }^{17}$ Cuatro pacientes continuaban con seguimiento en el servicio; no se ha observado progresión de la enfermedad o recaída en quienes se logró remisión.

\section{Conclusión}

Reportamos nueve casos de linfoma anaplásico de células grandes primario cutáneo CD30+, estudiados en un periodo de 24 años; predominaron las mujeres, la morfología y topografía fueron diversas, principalmente en el tronco y extremidades. El linfoma se manifestó principalmente con lesiones únicas papulares que evolucionaron a placas o lesiones tumorales eritemato-violáceas. Algunos linfomas se asociaron con enfermedad sistémica, a otras neoplasias como micosis fungoide y cáncer de próstata, y tuvieron respuesta variable al tratamiento. La importancia de conocer la incidencia y presencia de esta enfermedad radica en que el pronóstico depende del estadio clínico y en etapas tempranas es muy favorable.

\section{Bibliografía}

1. Cazzola M. Introduction to a review series: the 2016 revision of the WHO classification of tumors of hematopoietic and lymphoid tissues. Blood. 2016;127:2361-2364.

2. Yu J, Blitzblau R, Decker R, Housman D, Wilsn L. Analysis of primary CD30+ cutaneous lymphoproliferative disease and survival from the Surveillance, Epidemiology, and End Results Database. J Clin Oncol. 2008; 26:1483-1488.

3. Brown RA, Fernandez-Pol S, Kim J. Primary cutaneous anaplastic large cell lymphoma. J Cutan Pathol. 2017;44:570-577.

4. Kempf W, Pfaltz K, Vermeer M, Cozzio A, Ortiz-Romero P, Bagot M, et al. EORTC, ISCL, and USCLC consensus recommendations for the treatment of primary cutaneous CD30-positive lymphoproliferative disorders: lymphomatoid papulosis and primary cutaneous anaplastic large-cell lymphoma. Blood. 2011;118:4024-4035.

5. Yang S, Khera P, Wahlgren C, Ho J, Jukic D, Geskin L, et al. Cutaneous anaplastic large-cell lymphoma should be evaluated for systemic involvement regardless of alk-1 status: case reports and review of literature. Am J Clin Dermatol. 2011;12:203-209.

6. Liu HL, Hoppe RT, Kohler S, Harvell J, Reddy S, Kim Y. CD30+ cutaneous lymphoproliferative disorders: the Stanford experience in lymphomatoid papulosis and primary cutaneous anaplastic large cell lymphoma. J Am Acad Dermatol. 2003:49:1049-1058.

7. Vonderheid E, Sajjadian A, Kadin ME. Methotrexate is effective therapy for lymphomatoid papulosis and other primary cutaneous CD30-positive lymphoproliferative disorders. J Am Acad Dermatol. 1996;34:470-481.

8. Oliveira A, Fernandes I, Alves R, Lima M, Selores M. Primary cutaneous CD30 positive anaplastic large cell lymphoma: report of a case treated with bexarotene. Leuk Res. 2011;35:e190-e192.

9. Sheehy O, Catherwood M, Pettengell R, Morris TC. Sustained response of primary cutaneous CD30 positive anaplastic large cell lymphoma to bexarotene and photopheresis. Leuk Lymphoma. 2009;50:1389-1391.

10. French LE, Shapiro M, Junkins-Hopkins JM, Vittorio CC, Rook AH Regression of multifocal, skin-restricted, CD30-positive large T-cell lymphoma with interferon alfa and bexarotene therapy. J Am Acad Dermatol. 2001;45:914-918.

11. McGinnis K, Junkins-Hopkins J, Crawford G, Shapiro M, Rook A, Vittorio C. Low-dose oral bexarotene in combination with low-dose interferon alfa in the treatment of cutaneous T-cell lymphoma: clinical synergism and possible immunologic mechanisms. J Am Acad Dermatol. 2004;50(3):375-379.

12. Oregel K, Everett E, Zhang X, Nagaraj G. Complete response in a critically ill patient with ALK-negative anaplastic large cell lymphoma treated with single agent brentuximab-vedotin. Expert Rev Anticancer Ther. 2016:16:279-283.

13. Wehkamp U, Oschlies I, Nagel I, Brasch J, Kneba M, Günther A, et al ALK-positive primary cutaneous T-cell-lymphoma (CTCL) with unusual clinical presentation and aggressive course. J Cutan Pathol. 2015;42:870-877.
14. Duvic M, Talpur R, Wen S, Kurzrock R, David CL, Apisarnthanarax N. Phase II evaluation of gemcitabine monotherapy for cutaneous T-cell lymphoma. Clin Lymphoma Myeloma. 2006;7:51-58.

15. Rijlaarsdam JU, Huijgens PC, Beljaards RC, Bakels V, Willemze R. Oral etoposide in the treatment of cutaneous large-cell lymphomas. A preliminary report of four cases. Br J Dermatol. 1992;127:524-528.

16. Savage KJ, Harris NL, Vose JM, Ullrich F, Jaffe ES, Connors JM, et al. ALK- anaplastic large-cell lymphoma is clinically and immunophenotypically different from both ALK+ ALCL and peripheral T-cell lymphoma, not otherwise specified: report from the International Peripheral T-Cell Lymphoma Project. Blood. 2008;111:5496-5504.

17. Benner M, Willemze R. Applicability and Prognostic Value of the New TNM Classification System in 135 patients with primary cutaneous anaplastic large cell lymphoma. Arch Dermatol. 2009;145(12):1399-1404.

18. Bekkenk MW, Geelen FA, Van-Voorst-Vader PC, Heule F, Geerts M, Van-Vloten W, et al. Primary and secondary cutaneous CD30(+) lymphoproliferative disorders: a report from the Dutch Cutaneous Lymphoma Group on the long-term follow up data of 219 patients and guidelines for diagnosis and treatment. Blood. 2000;95:3653-3661.

19. Booken N, Goerdt S, Klemke CD. Clinical spectrum of primary cutaneous CD30-positive anaplastic large cell lymphoma: an analysis of the Mannheim Cutaneous Lymphoma Registry. J Dtsch Dermatol Ges. 2012;10:331-339.

20. Artemi P, Wong DA, Mann S, Regan W. CD30 (Ki-1)-positive primary cutaneous T-cell lymphoma: report of spontaneous resolution. Australas J Dermatol. 1997;38:206-208.

21. Biswas A, Tan B. Spontaneous regression of a childhood tumour with anaplastic histological features. Clin Exp Dermatol. 2012;38:318-320.

22. Paulli M, Berti E, Rosso R, Boveri E, Kindl S, Klersy C, et al. CD30/Ki-1-positive lymphoproliferative disorders of the skin: clinicopathologic correlation and statistical analysis of 86 cases: a multicentric study from the European Organization for Research and Treatment of Cancer Cutaneous Lymphoma Project Group. J Clin Oncol. 1995;13: 1343-1354.

23. Stein H, Foss HD, Dürkop H, Marafioti T, Delsol G, Pulford K, et al. $\mathrm{CD} 30+$ anaplastic large cell lymphoma: a review of its histopathologic, genetic, and clinical features. Blood. 2000;96:3681-3695.

24. Willemze R, Jaffe ES, Burg G, Cerroni L, Berti E, Swerdlow SH, et al. WHO-EORTC classification for cutaneous lymphomas. Blood. 2005; 105:3768-3785.

25. DeCoteau JF, Butmarc JR, Kinney MC, Kadin M. The t(2;5) chromosomal translocation is not a common feature of primary cutaneous CD30+ lymphoproliferative disorders: comparison with anaplastic large cell lymphoma of nodal origin. Blood. 1996;87:3437-3441.

26. Ishida M, Hodohara K, Yoshii M, Okuno H, Horinouchi A, Shirakawa A, et al. Primary cutaneous anaplastic large cell lymphoma occurring in an atopic dermatitis patient: a case report with review of the literature with emphasis on their association. Int J Clin Exp Pathol. 2014;7:1735-1741.

27. Shimizu Y, Tanae K, Takahashi N, Kohri M, Arai E, Bessho M, et al. Primary cutaneous anaplastic large-cell lymphoma presenting with hemophagocytic syndrome: a case report and review of the literature. Leuk Res. 2010;34:263-266.

28. Basheer A, Padhi S, Nagarajan R, Boopathy V, Mookkappan S, Igbal N. Hemophagocytic lymphohistiocytosis in association with primary cutaneous anaplastic large cell lymphoma. Case Rep Hematol. 2014; 2014:384123.

29. Kang JH, Lee JH, Park HJ, Cho BK, Song $\mathrm{CH}$, Ock SM, et al. Anaplastic lymphoma kinase-positive anaplastic large cell lymphoma arising in a patient with hypersensitivity to mosquito bites. Korean J Fam Med. 2015;36:35-41.

30. Hirata Y, Yokote T, Nishiwaki U, Tsuji M, Hanafusa T. Syndrome of inappropriate antidiuretic hormone secretion associated with primary cutaneous anaplastic large cell lymphoma. Br J Haematol. 2012;157:412.

31. Charafeddine KM, Farchoukh LO, Khalifeh I. Primary cutaneous anaplastic large-cell lymphoma occurring in a case of chronic myeloid leukemia in remission. J Cutan Pathol. 2012;39:884-886.

32. Yanagi T, Shimizu T, Kodama K, Nemoto-Hasebe I, Kasai M, Shimizu H. CD30-positive primary cutaneous anaplastic large-cell lymphoma and definite squamous cell carcinoma. Clin Exp Dermatol. 2009;34:e293-e294.

33. Newland KM, McCormack CJ, Prince H, Lade S. Cutaneous CD30 positive lymphoproliferative disorders with coexistent epithelial neoplasms: report of two cases. Australas J Dermatol. 2015;56:e83-e87.

34. Zhou P, Geng S, Li B, Wang J, Wang X, Xiao S. Keratosis lichenoides chronica in association with primary cutaneous anaplastic large cell lymphoma. Int J Dermatol. 2014:53:e109-e112.

35. Fletcher CL, Orchard GE, Hubbard V, Whittaker SJ, Edelson RL, Russell-Jones R. CD30(+) cutaneous lymphoma in association with atopic eczema. Arch Dermatol. 2004;140:449-454.

36. Di-Lernia V, Viglio A, Cattania M, Paulli M. Carbamazepine-induced, CD30+, primary, cutaneous, anaplastic large-cell lymphoma. Arch Dermatol. 2001;137:675-676.

37. Benner MF, Willemze R. Bone marrow examination has limited value in the staging of patients with an anaplastic large cell lymphoma first presenting in the skin. Retrospective analysis of 107 patients. Br J Dermatol. 2008;159:1148-1151. 